\title{
PRODUTIVIDADE E AFLATOXINA EM AMENDOIM CULTIVADO EM SISTEMAS CONSERVACIONISTAS DE MANEJO DO SOLO NA REFORMA DE CANA CRUA
}

Elcio Rios Pérez Leal ${ }^{1}$; André Samir Ucheli²; Olavo Betiol ${ }^{3}$; Larissa Morais da Silva Ambrosio ${ }^{4}$; Venancio Betiol ${ }^{5}$; Denizart Bolonhezi ${ }^{6}$

1'Graduando em Agronomia, CUML, Bolsista FUNDAG, Ribeirão Preto, denizart@iac.sp.gov.br; ${ }^{2} T e ́ c n i c o$, Cooperativa CASUL; ${ }^{3}$ Graduando em Agronomia, CUML, Bolsista FUNDAG, Ribeirão Preto; ${ }^{4}$ Eng. Agr., Bolsista de Aperfeiçoamento da FUNDAG, Ribeirão Preto; ${ }^{5}$ Eng. Agr., Bolsista de Aperfeiçoamento da FUNDAG, Ribeirão Preto; ${ }^{6}$ Pesquisador Cientíco, IAC/Centro de Cana, Bolsista do CNPQ, Ribeirão Preto.

RESUMO: A pesquisa foi instalada com o objetivo de estudar o efeito de manejos conservacionistas do solo versus manejo convencional, para amendoim cultivado na reforma de canavial localizado na Usina Califórnia, na região de Parapuã/SP. O experimento foi instalado com delineamento experimental de blocos ao acaso, com três tratamentos (preparo convencional, preparo reduzido e semeadura direta) e nove repetições, na safra 2017/18. Foram avaliadas características agronômicas, resistência mecânica do solo à penetração e alguns atributos físicos do solo. Apesar da maior compactação verificada nos manejos conservacionistas, não foram verificadas diferenças estatísticas entre os tratamentos quanto à produtividade de vagens e grãos, contudo os níveis de aflatoxina constatados nas amostras foram significativamente superiores no preparo de solo convencional.

Palavras-chave: Arachis hypogaea L., plantio direto, preparo reduzido.

\section{INTRODUÇÃO}

As alterações ocorridas nas últimas décadas no sistema de produção do amendoim, tais como: predomínio de cultivares rasteiros do tipo "runner", intenso uso de mecanização nos processos de colheita e modernização no sistema de recebimento, beneficiamento e secagem, determinaram o expressivo aumento da produtividade de amendoim em casca, que passou de $1529 \mathrm{~kg} \mathrm{ha}^{-1}$ na safra 1994/95 para $3600 \mathrm{~kg} \mathrm{ha}^{-1}$ na safra 2014/15. Esta mudança tecnológica foi verificada no final década de 70 nos EUA onde a produtividade média situa-se hoje em $4695 \mathrm{~kg} \mathrm{ha}^{-1}$, mas a cultura ainda tem potencial genético para ganhos em produtividade. Contudo, o custo de produção atualmente ultrapassa $\mathrm{R} \$ 5.800,00$ por hectare, sem incluir o custo do arrendamento que pode chegar a R \$ 1.500,00/ha. Uma das alternativas para reduzir o custo de produção pode ser a adoção de sistemas conservacionistas de manejo do solo, os quais podem diminuir os gastos com diesel expressivamente, pois os custos com combustível, máquinas e implementos representam $34,4 \%$ dos gastos totais da lavoura, considerando as duas últimas safras. 
Recentemente, foi introduzido dos EUA o equipamento denominado como Rip Strip ${ }^{\circledR}$, que realiza o preparo em faixas (entre 20 e $46 \mathrm{~cm}$ de largura por meio de quatro discos corrugados posicionados na vertical) e em profundidade por intermédio de haste subsoladora (até $45 \mathrm{~cm}$ de profundidade). SIRI-PRIETO et al. (2009) estudaram nas condições norte-americanas o uso deste implemento em comparação com a semeadura direta, em integração com pecuária e apesar do maior lucro obtido no preparo em faixas em comparação à semeadura direta, outros autores não observaram diferenças significativas quanto à produtividade, mas verificaram aumento na renda líquida na média de três anos na semeadura direta, além de menor população de tripes e incidência de Sclerotinia spp. (GODSEY et al., 2011). MCCARTHY et al. (2016) mencionam que o aumento da adoção de plantio direto nos EUA contribuiu para reduzir em 43\% a erosão entre 1982 e 2007, e destacam que para a cultura do amendoim são perdidos $5 \mathrm{~kg}$ de solo para cada $\mathrm{kg}$ de grão.

Para as condições, BOLONHEZI et al. (2017) concluíram através de resultados preliminares do projeto Amendoim na Palha, financiado pelo CNPQ e AGRISUS, que não ocorreu redução significativa na produtividade de vagens nos manejos conservacionistas em reforma de cana crua em solos arenosos, enquanto que para solos argilosos a diminuição ocorreu devido à falha no estande inicial e à compactação do solo. Dentre os desafios para a adoção de manejos conservacionistas para o amendoim destacam-se a presença de compactação e a incerteza sobre os níveis de aflatoxina nos grãos. Por conseguinte, ainda são necessárias pesquisas para elucidar quais os benefícios e os desafios do cultivo de amendoim em manejo conservacionista. Nesse sentido, o presente trabalho teve como objetivo estudar o efeito de diferentes tipos de manejos conservacionistas do solo para a cultura do amendoim na reforma de cana crua, sobre a produtividade e sobre o nível de aflatoxina nos grão, para as condições edafoclimáticas da região conhecida como Alta Paulista.

\section{MATERIAL E MÉTODOS}

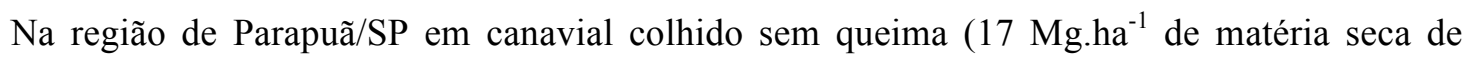
palhiço de cana) na Usina Califórnia, o experimento foi instalado em delineamento experimental em blocos casualizados com três tratamentos de manejo de solo (convencional, preparo reduzido e plantio direto) dispostos em nove repetições, conforme croqui apresentado na Figura 1. A semeadura foi realizada no dia 14/11/2018 utilizando-se a variedade de amendoim IAC-OL3. As parcelas com dimensões de 10,8 x $80 \mathrm{~m}$ foram instaladas mecanicamente. O tratamento convencional consistiu da passagem de grade intermediária, seguida por gradagem aradora, novamente uma gradagem intermediária e finalizado com gradagem niveladora. $\mathrm{O}$ tratamento denominado preparo reduzido, foi realizado com equipamento de quatro hastes fabricado pela Metalúrgica Carderolli. Semelhante ao Rip Strip $^{\circledR}$ da KBM Dumont, esse equipamento apresenta os mesmos elementos ativos (haste subsoladora, discos para destorroar), contudo apresenta maior peso e alguns detalhes diferentes na configuração da haste. A semeadura foi efetuada com semeadora da marca Jumil pneumática de quatro linhas, com 
disco corta- palha para plantio direto e haste escarificadora para distribuição do fertilizante. As avaliações agronômicas foram realizadas por ocasião da colheita (20/03/2018), que ocorreu quando as plantas atingiram o estádio de desenvolvimento R8 e R9, considerando também o teor de umidade dos grãos. Para quantificar a produtividade, após o arranquio e inversão, foram recolhidas duas leiras no comprimento da parcela, utilizando-se uma recolhedora modelo Twin Master e marca Colombo/Miac. A produção foi transferida para um transbordo, o qual foi pesado sobre "balança de sapata" com capacidade para 10 mil kg e resolução de 200 gramas.

Após pesagem, foi retirada uma amostra de amendoim de $25 \mathrm{~kg}$, de cada parcela, para posterior beneficiamento e determinação do rendimento de grãos. Das amostras de produtividade retiradas do campo, foi separada uma sub-amostra de $1 \mathrm{~kg}$ para determinação da aflatoxina, conforme teste padrão utilizado pelas beneficiadoras de amendoim. Os resultados foram submetidos à análise da variância e as médias comparadas teste de Tukey (5\%), utilizando para tal o software estatístico AgroEstat (BARBOSA \& MALDONADO, 2015).

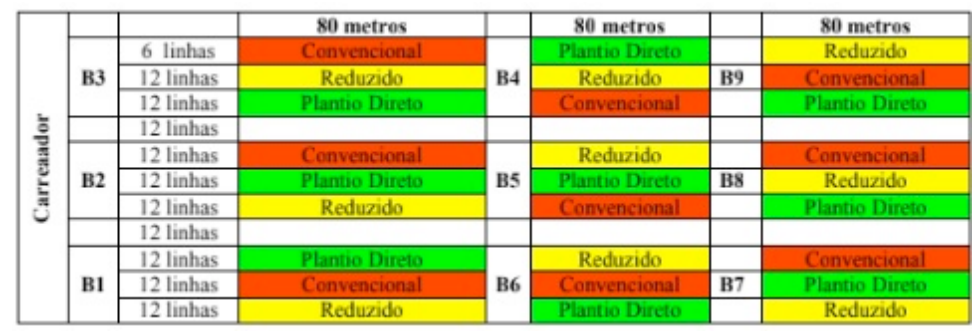

Figura 1. Croqui do experimento instalado em Parapuã/SP.

Verifica-se na Figura 2 a distribuição da chuva $(\mathrm{mm})$ e as temperaturas máximas e mínimas no período entre outubro de 2017 e março de 2018 para a localidade. Considerando o período compreendido entre 19/10/2017 e 12/03/2018, a chuva acumulada foi de $1016 \mathrm{~mm}$ e a média das temperaturas máximas e mínimas foram respectivamente 32,3 e $20,9{ }^{\circ} \mathrm{C}$, condição mais que suficiente para o desenvolvimento da cultura do amendoim. Todavia, notam-se períodos de eficiência hídrica ocorridos em janeiro de 2018 e segunda quinzena de março de 2018.

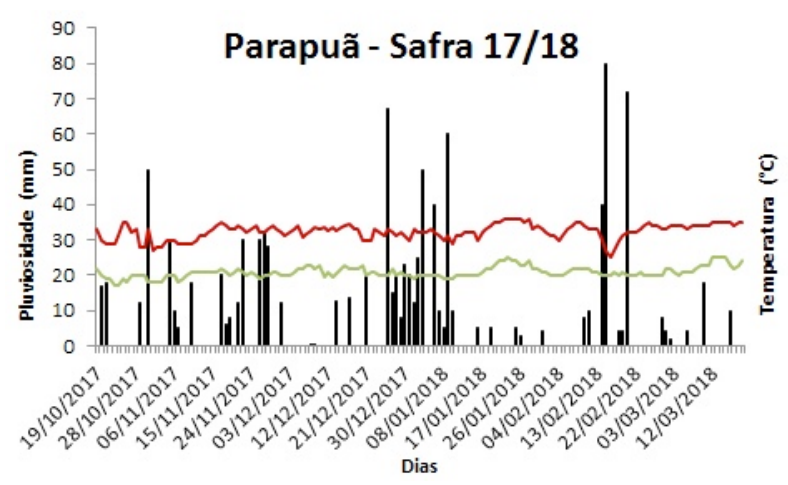

Figura 2. Distribuição de chuva e temperatura média na região de Parapuã/SP na safra 2017/2018. Fonte CIIAGRO/IAC. 


\section{RESULTADOS E DISCUSSÃO}

Nas Figuras 3 e 4 encontram-se os resultados referentes à produtividade de vagens e rendimento de grãos para o genótipo IAC-OL3. Verifica-se que não houve diferença estatística para a produtividade de vagens e grãos entre os tratamentos de manejos do solo. É importante esclarecer que essa produtividade é sem impurezas e descontada a umidade. Mesmo com produtividade um pouco menor, o fato de não acusar diferença estatística, pode auxiliar no estimulo para a adoção, pois o custo de produção pode ser expressivamente reduzido. MCCARTHY et al. (2016) esclarecem que entre 1980 e 2013, a emissão de gases do efeito estufa na cultura do amendoim foi reduzida de $1 \mathrm{~kg} \mathrm{CO}_{2}$ eq. $/ \mathrm{kg}$ de amendoim para $0,6 \mathrm{~kg} \mathrm{CO}_{2}$, uma redução de $40 \%$ e que pode ser parcialmente atribuída ao aumento da adoção de manejos conservacionistas para essa oleaginosa.

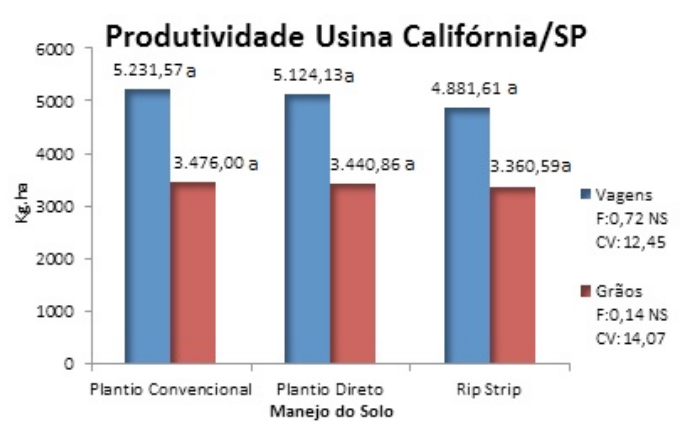

Figura 3. Produtividade nos diferentes sistemas de manejo de solo na reforma de canavial, no ensaio de Parapuã/SP.

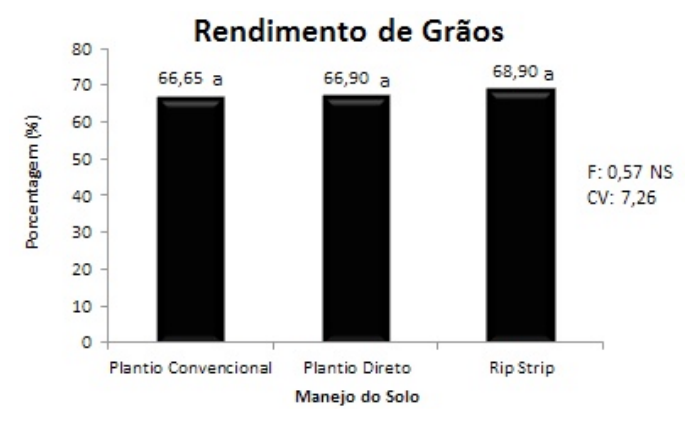

Figura 4. Rendimento de grãos nos diferentes sistemas de manejo de solo na reforma de canavial, no ensaio de Parapuã/SP.

Em relação aos níveis de aflatoxina (Figura 5), verifica-se redução expressiva no tratamento preparo reduzido em comparação com o convencional. Não foram encontrados resultados na literatura para comparar com os encontrados nessa pesquisa. Vale salientar que esse tipo de característica apresenta alta variabilidade espacial e fica difícil de quantificar em parcelas experimentais. Como nessa pesquisa foram utilizadas nove repetições no campo e a colheita representou a realidade do produtor, os resultados podem ser interpretados com relativa segurança. De acordo com BOWEN \& 
16 e 17 de agosto de 2018, centro de convenções da FCAV/UNESP - Câmpus de Jaboticabal, SP

HAGAN (2015), a ocorrência da infecção pelos agentes causais Aspergillus flavus (Link) e/ou Aspergillus parasiticus (Speare) ocorre em presença de altas temperaturas e baixa umidade na camada de solo referente à zona de frutificação do amendoim, sobretudo quando essas condições de estresse por seca ocorrem entre 40 e 75 dias antes da colheita. Provavelmente, os veranicos ocorridos favoreceram mais a conjunção de fatores favoráveis à infecção desses fungos no tratamento de preparo convencional do solo, pois nesse não havia resíduos da colheita de cana-de-açúcar.

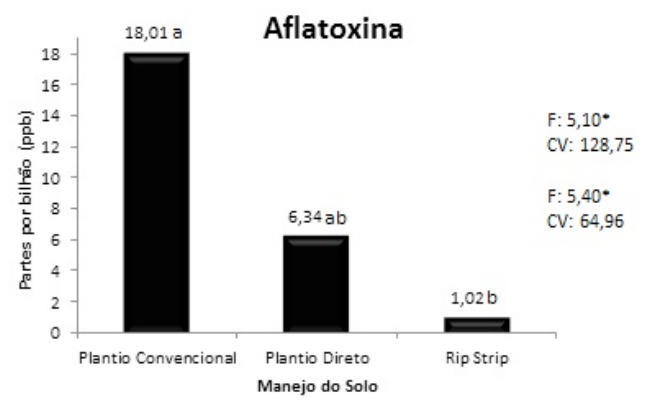

Figura 5. Teores de aflatoxina nos diferentes sistemas de manejo de solo na reforma de canavial, no ensaio de Parapuã/SP.

\section{CONCLUSÃO}

1- Não houve diferença estatística entre os sistemas de manejo do solo quanto à produtividade de vagens e aos componentes da produção.

2- Constatou-se maior nível de aflatoxina no sistema de manejo de solo convencional, provavelmente devido ao estresse hídrico na pré-colheita.

\section{REFERENCIAS BIBLIOGRÁFICAS}

BARBOSA, J.C.; MALDONADO Jr., W. AgroEstat - Sistema para Análises Estatísticas de Ensaios Agronômicos. UNESP, Jaboticabal, 2015, 396 p.

BOLONHEZI. D.; AMBROSIO, L.M.S.; BARINI, R.T.; BETIOL, V.; GONÇALVES, L.H.O.; SCARPELLINI, J.R.; BOLONHEZI, A.C. Peanut pod yield and soil compaction in Brazilian conservation agriculture system. VII, WORLD CONGRESS ON CONSERVATION AGRICUlTURE, Rosário, Argentina, 2017, Proceedings...Associacion Argentina de Productores en Siembra Directa (AAPRESID), Federação Brasileira de Plantio Direto na Palha (FEBRAPDP), Rosário, Argentina, 2017, p. 72-75. < http://proceedingswcca.worldpress.com/ > Disponível em $15 / 06 / 2018$.

BOWEN, K.L.; HAGAN, A.K. Temperature and moisture that affect aflatoxin contamination of peanuts. Peanut Science, v. 42, p. 121-127, 2015. 
GODSEY, C.B.; VITALE, J.; MULDER, P.G.; ARMSTRONG, J.J.; DAMICONE, J.; JACKSON, K.; SUEHS, K. Reduced tillage practices for the southwestern US peanut production region. Peanut Science, 38:41-47, 2011.

McCARTHY, J.A.; RAMSEY, S.; SANDERFUR, H.N. A historical analysis of the environmental footprint of peanut production in the United States from 1980 to 2014. Peanut Science, v. 43, p. 157$167,2016$.

SIRI-PRIETO, G.; REEVES, D.W.; RAPER, R.L. Tillage requirements for integrating winter annual grazing in peanut production: plant water status and productivity. Agronomy Journal, 101(6):1400$1408,2009$. 